secretions, and the entire point of view of pharmacology? Discoveries in the latter fields, concrete and pertinent facts, would carry us back to the tissues and back to the proceses of the nervous system, to nemropathology, structural and functional, and to psychopathology, and enlighten many dark corners therein. He who adheres to the classical problems as they lie within the teaching divisions of any science is not apt to change the face of that science.

$3 i$ Trowbridge street.

\section{CONTENT OF A COURSE IN PSYCHOLOGY FOR MEDICAL S'TUDENTS}

JOHN B. WATSON, PH.D.

Director, l'sychologien Laborntoly, Johns Hopkins University BALTIMORE

For several years I have been interested in the general subject of the relation of jsychology to medicine. It has long been a dream of mine that some day, when conditions are more favorable than they are at present, I should be able to persuade all of the rescarch students in psychology in my charge to take a large amount of their training in the medical school, if not the whole of the medical course. While such a.desideratum seems to be not immediately realizable there are certain signs at present which seem to show that the medical schools in their turn are becoming interested in our work and are not averse to seeing a closer relationship established between psychology and medicine. I believe indeed that interest has been so far awakened that some of the medical schools are willing to change their curriculum to such an extent as to admit a course in psychology.

The functional and practical phases of psyclology are now so much in the forefront of discussion that there is no need on my part to dwell on the increasing need that the medical student has for psychology. It has been this change within the aims and ideals of psychology itself which has made such a symposium as the present one possible. Psychology is ceasing to be a purely academic science and is now willing to study questions dealing with every-day life. 'This change in our ideas of what is of value in psychology has not been a sudden one, but even so, the knowledge of it is not so generally videspread among medical men as it might be.

The other papers in this symposium have not flattered psychology. They have shown that our psychologic texts and a good deal of the research work in psychology are not especiant:y valuable for the medical man. From the tone of the writings of certain medical men one would think that the days of psychology are numbered because of the failure of the psychologist to make his work directly applicable to the needs of medical men and especially to those of the psychoanalysts. But surely this is expecting too much of psychology. As I look back on our work for the last few years and on our attempts to teach psychology I confess that my conscience fails to prick me as much as it might. Surely medicine should not and need not expect to find its psychologic tools ready-made. The psychologist has had to adapt his tools from those supplied by physics and physiology. The recent psycho-analytic movement in medicine adds another large territory to the province of psychology. Special toots are needed. So fur psychology has not heen given, in certain medical circles at least, the credit which is its due for furnishing even unsatisfactory tools and methods which might be adapted to the needs of this body of workers. Surely it is evident that the methods used by Freud, and especially those of Jung, have been borrowed from psychology. I feel now that since this borrowing has been effected. those men have accomplished so much with the methods that it now behooves the psychologist to borrow them back again to retest them and to readjust them for use in psychologic research. It is this give-and-take spirit-a willingness to borrow and to lend - which will aid most in furthering research in the fields bordering on both psyehology and medicine. The perchologist, I believe, is far more willing to accept what psychotherapy and psycho-analysis can give him than the medical man following these lines is to accept what the psychologist has to offer.

The psycho-analyst to-day asserts his complete independence of psychology, he invents and assumes mental functious and mechanisms which, according to his point of view, cannot be subsumed under those now current in psychology, and has gone so far as to introduce a host of new terms relating to them into the already sinfully misused vocabulary of the psychiatrist. He speaks of "suppressed complexes." and "sexual traumas," acciuired sometimes in very early life, as actual living conscious factors. These are assumed to lave more importance for the ultimate development of behavior than all of the rest of the mass of habits which the subject has to form between youth (often childhood), when the suppression is supposed first to take place, and late adolescence when at the moment of "shock" the "suppression" becomes "effective." Probably the too ready attempt to make a complete and independent system of psycho-analysis and the failure on the part of the devotees of this new eult to maintain an intellectual freedom in their system have hindered a wide-spread and scientific study of the methods of Freud and Jung. This is a serious matter both for psychology and for medicine. I firmly believe that these methods contain within themselves the means of tremendously furthering medical practice, psychology and legal procedure.

But my purpose is not to criticize the methorls of the psycho-analyst. Let me say this, however, as being apropos of the type of course which I would suggest for the medical students: The psycho-analyst is using methods in a very crude and unsatisfactory way. $\mathrm{He}$ is building an enormous structure without looking carefully at the foundations. So long as we are content to use such terms as "suppression," "substitution." "symbolism," "latent" and "manifest" content "psychic censors," and the like, without further analysis, we are showing a willingness to revert to a type of "faculty psychology" which is worse than that which Herbart overthrew. What the psychologist would have the research ${ }^{1}$ psycho-analysts do is to give a careful statement in understandable terms of these processes of substitutions, sublimations and repressions. There is no question in my mind but that such phenomena when rightly understood are statable in terms of present-day psychology - in terms of memory processes, retention, habit formation, habit conflicts, etc. It is at this place that I believe normal psychology may offer the medical men crude tools which they themselves can readily fashion to suit their special needs and a terminology by means of which they can state their findings in such a way as to be intelligible to the psychologist.

1. I $\mathrm{nm}$ fully aware of the fact that there is a body of medical writers and medical practltioners who are willing to nccept and to use very crude methods without attempting every now and then to revise und to reconstiuct them. 
For some time we have been attempting at Johns Hopkins University to arrange for a closer relationship between work in the graduate school and the work in the medical school. As conditions now stand a sturlent may obtain his Ph.D. elegree in psychology and his medical degree in six years instead of seven, under certain conditions which I need not mention here. Furthermore, any of the medical men may take in the final fourth year an elective in psychology. With the coming of the psychiatric elinic this relationship will be made still closer.

In attempting to give my ideas on this subject a clearer statement, I feel handicapped by the existing disparity in the psychologic training of the medical men before they enter on their medical studies. I slall take it for granted now that the students in medicine have had in their premedical work the equivalent of at least a three-months' course in elementary psyclology, having as a text-book some psychology like that of Angell, Judd, or 'Titchener."

A second difficulty that hampers us is the way in which anatomy (especially neurology) and physiology are taught. I feel that ton much time is given to anatomy or ratler to the type of anatomy that we have taught in medical schools, and when I say this I feel that a good many of the professors of anatomy in the country will agree with me. The student comes out of his course in anatomy with very little notion of the way the structures work, with very little notion of the integrated systems of conduction in the nervous system; and when he gets to physiology his attention is again attracted to the details of organs and not to the way in which the organs work when put together. I say this in all humbleness. It would be presumptuous for me to attempt to reconstruct the first-year courses in anatomy and physiology for the medical student, but the need for some change is imperative if we are to find a place for psychology in the medical curriculum. I am more and more convinced that the nervous system is badly taught by the psychologist and that in the future it would be well for him not to have less knowledge of the nervous system, but to try to teach it less and to confine his teachings more to the psychologic material. I do not believe any psychologist really wants to teach sense-organ structure or the architecture of the central nervous system. He ought to realize, and I think he does, that these subjects can be better taught by the men who are responsible for research in them.

Having relieved my mind of some of the difficulties in the way of teaching psychology in the medical schools, I may say, further, that before the course I have in mind will ever become popular with the medical student there must come some change in the ideals fostered by his whole course of instruction. The medical student must be taught that no matter whether he is specializing in surgery, obstetrics or psychiatry, his subjects are human beings and not merely objects on which he may demonstrate his skill. This shift in his ideas of value will lead him to feel the need of psychologic training and to accept that training in the fields of habit formation, association, memory and emotion.

I suggest that the course should require three periods each week; two laboratory periods of two hours each and one lecture, the course to continue for one full vear, proably as an elective in the third year. I think that

2. I entirely agree with the remurks made by Professor Angell In legurd to the thoroughness of such an undergraduate course and the brond-minded way in whlch it should be conducted. It is, how ever, not feaslble, even if ndvisable, to separate the undergraduate training in psychology of the medlcal men from that of the men who are to follow other vocations.

Downloaded From: http://jama.jamanetwork.com/ by a UQ Library User this should represent the minimum of time which should be devoted to psychology in the medical school. If the laboratory work is to be touched on at all, then let us do the work with some degree of thoroughness. Unless this amount of time can be given over to the work I should. faror simply a lecture course covering the more important topics in psychology. While I fully realize the fact that psychology and psychologists have more or less wasted an enormous amount of time on the topic of sensation, I feel, nevertheless, that some experiments should be given in the topic of sensation. I suggest, therefore, that inasmuch as the whole ground cannot be covered, we centralize our efforts in sensation on two senses-vision and hearing. With a proper apparatus for the mixing of spectral colors the work in color-vision, including the tests on color-blindness, can be accomplished in three weeks' time. If we have to send the student to the color-wheel and have him go through the endless mill described by 'T'itrhener, he will get discouraged and waste the better part of three months and still come out with a very limited knowledge of the main features in the study of vision.

'The study of auditory sensation, in so far as its data would be valuable for the medical student, can likewise be completed in a short space of time. One needs for this work a good set of forks, the Edlemann's testingforks, a set of differential forks-the siren, the Lehmann acoumeter and some of the more common pieces of apparatus which every psychologic laboratory now contains. By means of these simple instruments we could give the medical student a command of the method of testing limits of tone, tone islands, pitch differences, difference tones and the like. The lecture-work going along with the study of sensation should condense the work in the sense fields. It should confirse itself to the data and should leave out of discussion the endless details of color theories, and theories of audition. 'The emphasis should be placed on the function and use of these two sense-organs and on the methods of studying them.

I think that this short course in sensation would give the medical student some notion of the proper setting and control of a psychologic experiment.

These experiments on the sense fields should, in my opinion, be followed by a thorough study with laboratory and clinical work of the Binet-Simon tests, this work to be supplemented on the experimental side by such studies as "Thoindike is making on the "curve of work," initial spurts in work, spurts after interruption, end-spurts. etc. -in other words, by tests which show the part that fatigue, disturbances and emotional factors play in the normal on-going of mental work. Although the work on "fatigue" in the usual sense is in a chantic condition at present, I am not sure that we are justified in leaving it out of our course. I have the feeling that if psychologists will interest themselves more in the acquisition and control of motor processes rather than in the "pattern" or "content of consciousness" when entering on studies in fatigue, there will be brought about a rehabilitation of the ergographic methods of experimentation which will be to the advantage both of psychology and medicine.

In my judgment this work on mental tests should be followed by experimental studies in the acquisition and retention of skilful acts; these studies should be made uncler several different sets of conditions. This type of experimentation, showing the different stages and methods of acquiring accommodations, the distribution of effort in learning, the short cuts in learning, etc., 
should be of tremendous interest to the psychiatrist. It paves the way for the normal understanding of lack of interest at certain stages of development (apathy as shown in "resting places" and "plateaus," the understanding of "bungling," and "conflicts," the stamping in and retention of wrong methods of response and the effect of emotional states on the acquisition and exercise of habit). Furthermore, it shows when properly conducted, even on adult subjects as no other form of experiment does, the complete transition from a random unskilful type of response (infantile) to one essentially automatic. Certuinly no medical man should deem himself prepared to give instruction in the subjects of hypnosis and the "subconscious" without a somewhat extended training in the rise of normal automatisms.

Our medical student will be prepared by this time to enter intelligently on the study of the normal process of association, menory and retention. My plan would be to make these studies purely "objective"-a definite task should be set. words, phrases and various other material presented; then the time of learning under ordinary conditions and under conditions of excitement (obtained by "rushing," interruption, ete.), the rate of learning and the errors in lenrning should be measured as any other biologic function is measurer. Retention after definite interval under both normal conditions and under conditions of strain and excitement should be tested in a similar manner. Memory in the narrower sense ("associations with time, place and emotional setting") can very ensily be tested hy the picture method or by presenting concrete situations-now largely used in formany in the psychologie training of students of law. ${ }^{3}$ Definite intervals are allowed to elapse and then the accuracy of reproduction is tested by allowing the observer to give oral or written statements. The work should be amplified by testing the effect on reproduction of the various ways in which questions may be put to the olserver. The word-association method can be conveniently made use of in this type of memory study. If these experiments on association, memory and retention are at all thoroughly made they will not only yield the medical student the mastery of the technic in this extremely uscful field, but will teach him how to handle his patient and to prepare an intelligent record of his case. ${ }^{*}$

I feel that the course should contain a few lectures and several experiments on normal reaction time.' Without eriticizing the refinements in the methods of the normal psychologist, I think we can safely admit that the medical student does not need to measure reaction times by units as small as a sigma. At the same time I am not in favor of putting a stop-watch in his hands without at the same time telling him a little about the factors. which influence reaction times, their normal variability, especially in untrained subjects and the individual peculinrities of different subjects in this and other respects.

3. It hus heen n matter of Interest to me that psycho-analysts have not more whdoly glisised the possibilities in this method for the minviling of "siimplessed complexes."

4. One of the incldental but not lesst valuable results from the pxperiments in nswocintion with nonsense material (Ebblnghaus) would be the demonstrution to the medical student that there is nlways n normal process of forgetting occuring without the intrusion of supplessed sexuml complixis. It would not be surprising wher that if after he had learned a serles of slxteen nonsense syllables and found that after " few hours he could not reall one of them but could relearn the series in one-third of the original time of learning, lie should come to the conclusion that a good many thises could be necomplished by the normal functioning of the nevous system without the necessity of positing a "consclous unconsclous content"- the "subconsclous" to aid it.

Downloaded From: http://jama.jamanetwork.com/ by a UQ Library User
With this foundation in practical psychology (not "applied") I think we can safely turn the medical student interested in psychopathology and psycho-anal reis over to the psychiatric clinic. There, surely, is the place for him to olstain his knowledge of hypnotism, multiple personalities, suggestion and aphasia. ${ }^{\circ}$ Only in the clinie. can be obtained the material for study; without the individual study of cases all the lecture work in the world is unavailing.

While there is no manual of psychology dealing expressly with the material needed by the medical student, I feel sure that such will be fortheoming at an carly date if psychologists and medical men will agree specifically on the necessary content of such a book.

In conclusion $I$ wish to express my appreciation of the work of the psychiatrists for the interesting possibilities of researel and interpretation which they are affording the normal psychologist. It is largely by reason of the brond-minded character of the work of Adolf Meyer, Foch, Freud and Jung that the normal psychologist has been foreed out of his academic reserve and into an active participation in the work of psychopathology.

\section{THE NEW PSYCHOLOGY AND THERAPEUTICS}

MORTON PRINCE, M.D.

Professor of Neurology, llufts College Medical School BOSTON

The point of this symposium, as I understand it, is the relation between normal psychology and medical education. If by normal psychology is meant that which is taught in the ordinary academic curriculum as expounded in the more commonly used text-books, the question is a very simple one. At least it is such if $\mathrm{I}$, as a teacher and practitioner of medicine, correctly apprehend the problems of pathologic psychology. I say that it is a simple question for I am unable to sce any particularly close relation between this kind of normal psychology and the problems of medicine, and particularly psychotherapy. I would not say that normal psychology as commonly taught has no value whatsoever for the student of psychopathology and for him who is concerned with the healing of the sick organism. That would be an extravagant statement. If one digs through a text-book of normal psychology one finds here and there some observation, some fact, some theory, som? principle which is of help in elucidating a pathologic condition, or which one may make use of for therapentic purposes. But I. think $I$ am right in saying that one discovers these bits of gold in a massive collection of useless bits of information, because one has learned to know their meaning and value from the knowledge gained by one's studies in abnormal conditions, and not the reverse; that is to say, one's understanding of pathologic processes has not been gained from a knowlelge of normal psychology.

For the most part the mass of facts gained from normal psychology is useless for the understanding of medical problems which include both pathologic processes and practical therapeutics. The problems with which normal psychology concerns itself are of little interest

5. The only subject I should wish to have excluded as a special tople would be that of the "subconscious." Surcly we gain nothing by this concept. We cun study the visible and tranglble effect of suppresslons, tangles, confliclling habits and the like without posit: ling a "subconscious." Iersondly I feel that the introduction of such a concept is as detimental to the advance of psychology analysis as is the discussion of those philosophic remnants--psychophysical parallellsm and interaction. 